\section{Mentalizing, but Not Autistic Traits, Predicts Religious Belief in a Sample of Healthy Japanese Youth}

\author{
Tatsunori Ishii* \\ Tokyo Seitoku University, Hoshina 2014, Yachiyoshi, Chiba 276-0013, \\ Japan \\ "Author for correspondence (t.ishii1108@gmail.com)
}

The present research examined the hypothesis that religious belief is derived from humans' mentalizing ability in the context of East Asia where polytheistic religion is the mainstream. Two studies were conducted with a Japanese healthy sample, and both revealed that contrary to the hypothesis, autistic traits did not predict religious belief, whereas mentalizing predicted increased religious belief as expected. These findings suggest that further empirical and theoretical investigations on the origin of religious belief are needed.

\section{Keywords}

mentalizing, religious belief, autistic traits

\section{Introduction}

The cognitive and evolutionary origin of religious belief, belief in superhuman beings or spirits who have supernatural power, such as creating the universe or controlling human fates, have been investigated in recent years (e.g., Norenzayan, Gervais, \& Trzeniewski, 2012; Willard \& Norenzayan, 2013). These studies suggest an emerging consensus that religious belief is derived from humans' unique social cognitive ability: mentalizing (Gervais, 2013). Mentalizing is the ability to infer and understand others' mental states, and because this ability enables humans to perceive supernatural agents, such as gods or spirits with human-like mental states, humans come to believe in their existence. Previous studies (e.g., Willard \& Norenzayan, 2013) have demonstrated that individual differences in mentalizing predict an increased religious belief. Meanwhile, Norenzayan et al. (2012) showed that adolescents with autism who have reduced mentalizing ability have less religious belief, and that mentalizing mediates this relationship regardless of gender.

These investigations ought to contribute to the field of evolutionary behavioral sciences. It has been argued that mentalizing ability has evolved so that humans can maintain their social relations and survive (e.g., Barrett, Cosmides, \& Tooby, 2010). If religious belief is derived from mentalizing ability, religion, which is unique to human culture, can be elucidated from the viewpoint of evolutionary science.

Notably, most of the previous studies were conducted in Western countries, where monotheism, such as Abrahamic religions, is the mainstream religion. Thus, examining the relationship between mentalizing and religious belief in other cultural areas, such as East Asia, where polytheism (e.g., Buddhism, Shinto) is the mainstream, has academic merit.

This study aims to examine the relationship between mentalizing and religious belief in East Asia, particularly Japan. Although only a few Japanese adults profess to be religious, they nonetheless acknowledge the importance of religious faith and have respect for gods or spirits (Hayashi, 2006). Moreover, it was suggested that Japanese adults have animistic thinking: the tendency to regard inanimate objects as living (Ikeuchi, 2010). It can be hypothesized that mentalizing ability explains the individual differences in religious belief among young Japanese people.

To test the hypothesis, two studies were conducted employing the procedure of Norenzayan et al. (2012). Study 1 examined the relationship between autistic traits and religious belief in a sample of healthy Japanese youth. Adolescents with autism have a low mentalizing ability (e.g., Baron-Cohen \& Wheelwright, 2004), and thus, autistic traits could predict reduced religious belief. In study 2 , assessing mentalizing directly, the relationships among mentalizing, autistic traits, and religious belief were investigated. According to previous findings, autistic traits predict reduced religious belief, and mentalizing mediates this relationship (mentalizing predicts increased religious belief)

\section{Study 1}

(a) Method

\section{Participants}

Ninety-two undergraduates at Sophia University in Japan $\left(M_{\text {age }}=19.9, S D_{\text {age }}=1.56,33\right.$ males, 58 females, 1 unknown) participated in exchange for extra credit in an introductory psychology class.

\section{Materials and Procedure}

First, participants answered the demographic questions (age and gender). Next, they rated their agreement (15) with a nine-item religious belief measure that was created for this study based on established Japanese scales. These measures consisted of two scales: the subscale of the Animism Scale for Adults (Ikeuchi, 2010), called "the apotheosis of natural products (three items)" and the subscale of the Attitudes Toward Paranormal Phenomena Scale short edition (Sakata, Kawakami, \& Koshiro, 2012), called "belief in spirituality (six items)." Then, the participants answered the Autism-Spectrum Quotient (AQ) Japanese version (Wakabayashi, Tojo, Baron-Cohen, 
Table 1. Descriptive statistics and bivariate correlation coefficients in Study 1.

\begin{tabular}{lcccc}
\hline Variable & & 1 & 2 & Gender \\
\hline 1. AQ & $M=21.11(S D=6.49)$ & .77 & -.13 & .08 \\
2. Religious Belief (9 itmes) & $M=3.15(S D=0.85)$ & & .89 & .17 \\
\hline
\end{tabular}

Note. The values in the diagonal cells are alpha cofficiants.

\& Wheelwright, 2004) to measure individual differences in autistic traits. The full information of materials can be found in Supplemental File.

\section{(b) Results and Discussion}

Multiple regression analysis was used to test if the AQ score predicted the religious belief score. Gender (coded as $0=$ male, 1 = female) was also entered as an independent variable as it is a confounding variable; males showed higher AQ scores than females (Wakabayashi et al., 2004). According to the hypothesis, the AQ score should predict the religious belief score negatively. The results of the analysis showed that neither the AQ score $(\beta=-0.06, S E$ $=0.10, p=.573)$ nor gender $(\beta=0.40, S E=0.21, p=.061)$ were a significant predictor of the religious belief score. The descriptive statistics were summarized in Table 1.

Study 1 suggests that religious belief is not predicted by autistic traits. However, the study had a small sample size. The post hoc effect size in multiple regression with two independent variables (Cohen's $f^{2}=.045$ ) was so small that the statistical power was insufficient (post hoc power $=.416$ ). To reach the significance level, a larger sample size was needed. Another possibility is that the nine-item measure of religious belief had a low validity. Although the internal consistency was sufficient, the items were different from the original ones used in Norenzayan et al. (2012). This difference may be the reason that the results of study 1 did not support the hypothesis. These possibilities were examined in study 2, apart from the relationships among the autistic traits, mentalizing, and religious belief.

In addition, two more demographic questions about participants' nationality and religious affiliation were added since such information can influence the interpretation of the results in this study. For example, if a large number of students from Western countries (e.g., exchange students) participated, the purpose of this study will not be achieved. Additionally, it will be helpful for understanding the implication of the results to confirm the number of participants who have faith in religion.

\section{Study 2}

(a) Method

Participants

The power analysis was conducted using G*Power to determine the sample size in multiple regression with two independent variables (autistic traits and gender for control). The significance level was set at .05 , power at .80 (medium power), and the effect size at .045 based on the results of study 1 . The result indicated that this study needed 218 participants.

Undergraduates at Sophia University were recruited in exchange for extra credit in an introductory psychology class. However, only 148 students participated $\left(M_{\text {age }}=19.0\right.$ years, $S D_{\text {age }}=1.12,59$ males, 88 females, 1 unknown). Ishii LEBS Vol. 8 No.2 (2017) 32-35
Although this sample size was insufficient to examine the relationship between autistic traits (AQ) and religious belief, it may be adequate to examine the relationship between mentalizing and religious belief: when the significance level was set at .05 , power at .80 , and the effect size at 0.15 (medium effect size), the sufficient sample size was 68 . Hence, no additional participant was recruited, and a supplementary analysis combining the data set of studies 1 and 2 was planned to test the relationship between autistic traits and religious belief.

\section{Materials and Procedure}

First, participants answered the demographic questions (age, gender, nationality, and religious affiliation). Next, they rated their agreement (1-5) with 13 items that measure individual differences in religious belief, which included the same nine items used in study 1 and four items on the belief in God measure used in Norenzayan et al. (2012, studies 1 and 2). Then, the participants answered the AQ Japanese version and the short form of the Empathy Quotient Japanese version (EQ-short, Wakabayashi, Baron-Cohen, \& Wheelwright, 2006; Wakabayashi et al., 2006). The EQ is used to measure the ability to infer and understand the mental states of others and to react appropriately to them in everyday life (e.g., Norenzayan et al., 2012; Willard \& Norenzayan, 2013). The full information of materials can be found in Supplemental File.

\section{(b) Results and Discussion}

Based on the answers to the demographic questions, the data from eight participants were excluded because their nationalities were not Japanese. Of the remaining 140 participants, only nine affirmed having faith in religion (six Buddhists, three Christians).

In a multiple regression model with the AQ score and gender $(0=$ male, $1=$ female, control variable) predicting the religious belief score $\left(f^{2}=.066\right.$, post hoc power $\left.=.740\right)$, the AQ score did not predict religious belief $(\beta=0.001, S E$ $=0.08, p=.988)$, but gender predicted increased religious belief $(\beta=0.49, S E=0.17, p=.005)$. Meanwhile, the EQ score was a significant predictor of the religious belief score $(\beta=0.20, S E=0.08, p=.019)$, along with gender $(\beta$ $=0.53, S E=0.17, p=.002)$, in a model with the EQ score and gender predicting the religious belief score $\left(f^{2}=.127\right.$, post hoc power $=.967)$. Further, the AQ score $(\beta=-0.29$, $S E=0.08, p=.001)$ was a significant predictor of the EQ score regardless of gender $\left(f^{2}=.122\right.$, post hoc power $=$ 950). The same results were obtained when the religious belief score was calculated either using the nine items in study 1 or the five items on the belief in God measure (see Supplemental File). The descriptive statistics were summarized in Table 2.

In study 2, the AQ score did not predict the religious belief score even after the modifications made to address 
Table 2. Descriptive statistics and bivariate correlation coefficients in Study 2

\begin{tabular}{lccccccc}
\hline Variable & & 1 & 2 & 3 & 4 & 5 & Gender \\
\hline 1. AQ & $M=20.07(S D=5.92)$ & .70 & -.31 & -.03 & -.02 & -.03 & -.11 \\
2. EQ & $M=19.15(S D=7.41)$ & & .86 & .22 & .19 & .21 & .10 \\
3. Religious Belief (13 items) & $M=3.22(S D=0.70)$ & & & .85 & .96 & .76 & .26 \\
4. Religious Belief (9 items) & $M=3.23(S D=0.86)$ & & & & .89 & .56 & .20 \\
5. Religious Belief (5 items) & $M=3.23(S D=0.71)$ & & & & & .53 & .30 \\
\hline
\end{tabular}

Note. The values in the diagonal cells are alpha cofficiants.

the problems in study 1 . Thus, having autistic traits may not be a predictor of religious belief, contrary to the hypothesis. This conclusion was supported by the supplementary analysis. Using the combined data set of studies 1 and $2(n=232)$, the religious belief score $(9$ items) was regressed by the AQ score and gender. Then, gender $(\beta=0.37, S E=0.13, p=.006)$, but not the AQ score ( $\beta=-0.03, S E=0.07, p=.691)$, was found to predict the religious belief score. Meanwhile, study 2 also suggested a positive relationship between mentalizing and religious belief, as hypothesized. Consistent with the findings of previous studies (e.g., Norenzayan et al., 2012), women were more religious than men, although this relationship was not the focus of this study.

\section{General Discussion}

The present study aimed to examine the relationship between mentalizing and religious belief in Japan. Based on the findings in Norenzayan et al. (2012), this work hypothesized that having high autistic traits (AQ) predicts reduced religious belief, whereas mentalizing ability (EQ) predicts increased religious belief because of the negative correlation between autistic traits and mentalizing ability. Results of the two studies conducted in this research mostly support these hypotheses, but the relationship between autistic traits and religious belief was not established, as opposed to Norenzayan et al. (2012).

One possibility is that the results were influenced by the methodological differences between the present study and that by Norenzayan et al. (2012). For example, as mentioned in the introduction, only a few Japanese adolescents profess faith in religion, unlike in Western countries. In study $2,93.6 \%$ of participants reported having no religious affiliations, compared with $26.0 \%$ in Norenzayan et al. (2012, study 2). The high rate of nonreligious participants could be a cause of the floor effect on the religious belief score, in which case the hypothesis would not be supported. However, this was not observed in the current work. The religious belief score showed no floor effect: the average was around 3 (3.06-3.23), and SD was less than $1(0.67-0.85)$ in the five-point scale. This finding means that about half of the Japanese adolescents, even those without a religious affiliation, expressed their agreement with the statements on the existence of supernatural agents.

Another possibility is that the relationship between autistic traits and religious belief may be so weak that it could only be detected with a larger sample size. Indeed, Norenzayan et al. (2012) recruited 327-706 participants in their series of studies. Although the sample size of the supplementary analysis was adequate to detect a small effect size, it may be worth conducting another study with a much larger sample size.

Finally, viewed from the opposite perspective, the results of this study may challenge the theory that religious belief is derived from mentalizing ability (e.g., Gervais, 2013; Norenzayan et al., 2012). Jack, Friedman, Boyatzis, $\&$ Taylor (2016) reported that the relationship between religious and spiritual beliefs (measured with the item "Do you believe in the existence of either God or a universal spirit?") and the AQ or EQ disappeared after the empathic concern (measured with Interpersonal Reactivity Inventory [Davis, 1983]) was taken into account, and discussed that religious belief is linked to empathic concern directly and not mentalizing ability. Consistent with this discussion, the present study also failed to demonstrate the AQ as a significant predictor of religious belief. In other words, this result could be interpreted as supporting Jack et al. (2016). Of course, this study showed that the EQ is a significant predictor of religious belief. This result is not consistent with the discussion in Jack et al. (2016); rather it supports the theory of the link between religious belief and mentalizing.

Overall, the present study showed that mentalizing ability predicts religious belief among Japanese adolescents. This result lends support to the hypothesis that mentalizing ability is crucial to understanding why people believe in supernatural agents. Further, it suggests that the origin of religious belief is not culture-specific. However, contrary to the hypothesis, this study failed to show autistic traits as predicting religious belief. It will be necessary to conduct further studies that examine the hypothesis, and also to refine the theory, especially how empathic concern relates to the relationships among autistic traits, mentalizing, and religious belief.

\section{Supplementary material}

Electronic supplementary material is available online.

\section{References}

Baron-Cohen, S., \& Wheelwright, S. (2004). The empathy quotient: an investigation of adults with Asperger syndrome or high functioning autism, and normal sex differences. Journal of Autism and Developmental Disorders, 34, 163-175. (doi: 10.1023/ B:JADD.0000022607.19833.00)

Barrett, H. C., Cosmides, L., \& Tooby, J. (2010). Coevolution of cooperation, causal cognition and mindreading. Communicative \& Integrative Biology, 3, 522-524. (doi: 10.4161/cib.3.6.12604)

Davis, M. H. (1983). Measuring individual differences in 
empathy: evidence for a multidimensional approach. Journal of Personality and Social Psychology. 44, 113-126. (doi: 10.1037/0022-3514.44.1.113)

Gervais, W. M. (2013). Perceiving minds and gods: how mind perception enables, constrains, and is triggered by belief in gods. Perspectives on Psychological Science, 8, 380-394. (doi: 10.1177/1745691613489836)

Hayashi, F. (2006). A study of religious faith and religious feelings. The Japanese Journal of Behaviormetrics, 33, 13-24. (doi: 10.2333/jbhmk.33.13) (in Japanese with an English abstract)

Ikeuchi, H. (2010). Animistic thinking in adults: the memorial service for dolls as a voluntary loss. Japanese Journal of Social Psychology, 25, 167-177. (doi: 10.14966/jssp.KJ00006203282) (in Japanese with an English abstract)

Jack, A. I., Friedman, J. P., Boyatzis, R. E., \& Taylor, S. N. (2016). Why do you believe in God? Relationships between religious belief, analytic thinking, mentalizing and moral concern. PLoS ONE, 11: e0149989. (doi: 10.1371/journal.pone.0149989)

Norenzayan, A., Gervais, W. M., \& Trzesniewski, K. H. (2012). Mentalizing deficits constrain belief in a personal god. PLoS ONE, 7, e36880. (doi: 10.1371/ journal.pone.0036880)

Sakata, H., Kawakami, M., \& Koshiro, E. (2012). Constructing attitudes towards paranormal phenomena scale (APPle) short edition (1): attitudes towards paranormal phenomena (29). The 76th annual convention of the Japanese Psychological Association. 238. (in Japanese)

Wakabayashi, A., Baron-Cohen, S., \& Wheelwright, S. (2006). Individual and gender differences in empathizing and systemizing: measurement of individual differences by the Empathy Quotient (EQ) and the Systemizing Quotient (SQ). The Japanese Journal of Psychology, 77, 271-277. (doi: 10.4992/ jjpsy.77.271) (in Japanese with an English abstract)

Wakabayashi, A., Baron-Cohen, S., Wheelwright, S., Goldenfeld, N., Delaney, J., Fine, D., ... Weil, L. (2006). Development of short forms of the Empathy Quotient (EQ-short) and the Systemizing Quotient (SQ-short). Personality and Individual Differences, 41, 929-940. (doi: 10.1016/j.paid.2006.03.017)

Wakabayashi, A., Tojo, Y., Baron-Cohen, S., \& Wheelwright, S. (2004). The Autism-Spectrum Quotient (AQ) Japanese version: evidence from highfunctioning clinical group and normal adults. The Japanese Journal of Psychology, 75, 78-84. (doi: 10.4992/jjpsy.75.78) (in Japanese with an English abstract)

Willard, A. K., \& Norenzayan, A. (2013). Cognitive biases explain religious belief, paranormal belief, and belief in life's purpose. Cognition, 129, 379-391. (doi: 10.1016/j.cognition.2013.07.016) 